\title{
Grimalt, J. (2020). Mapping Musical Signification. Cham: Springer, 402 pp. ISBN: 978-3-030-52496-8.
}

Editada por Springer en 2020, con prólogo de Robert S. Hatten y ambicioso título, esta reciente publicación resulta atractiva tanto para profesionales e investigadores del campo como para iniciados e incluso estudiantes de grado superior con interés en la emergente disciplina de la Significación Musical.

Mapping Musical Signification es, en palabras del autor, el resultado de años de investigación en el terreno de la significación musical. Se trata de una guía para conseguir un acercamiento comprometido en la interpretación de la música clásica occidental y que integra el estudio de la significación musical en el análisis. El libro podría definirse como el punto intermedio entre un ensayo y un tratado. Presenta un lenguaje claro, pero no huye de la complejidad técnica que exige la especialización en el tema de estudio.

Uno de los principales atractivos del libro es que ofrece una doble lectura: por un lado, se puede emplear como libro de consulta, gracias al índice general de la p. 23 y a una meticulosa lista alfabética de ejemplos musicales (p. 369) que, en la edición digital, permite acceder a cada página citada con un clic. Por último, el libro cuenta con un detallado índice de términos y autores (p. 395).

Además, el libro no se presenta únicamente como un glosario de términos, sino que sigue un orden lógico que permite una lectura de principio a fin. Grimalt no sólo define e ilustra musicalmente cada referencia o signo musical, sino que presenta su genealogía, es decir, la procedencia histórica del gesto en cuestión y cómo ha ido evolucionando con la práctica musical.

\begin{tabular}{|c|c|c|c|}
\hline \multirow{8}{*}{$\begin{array}{l}\text { MaPPING Musical } \\
\text { Signification }\end{array}$} & \multirow[t]{3}{*}{ Signs } & Chapter 1 & Musical signs \\
\hline & & Chapter 2 & Madrigalisms, rhetorical figures \\
\hline & & Chapter 3 & $\begin{array}{l}\text { References (topoi), semantic } \\
\text { fields }\end{array}$ \\
\hline & \multirow{5}{*}{$\begin{array}{l}\text { Sets of } \\
\text { signs }\end{array}$} & Chapter 4 & Sacred references \\
\hline & & Chapter 5 & Martial references \\
\hline & & Chapter 6 & Lyricism, Pastoral. \\
\hline & & Chapter 7 & Dance references \\
\hline & & Chapter 8 & Theatrical references \\
\hline
\end{tabular}

Tabla 1. Tabla de contenidos de Mapping Musical Signification. 


\section{RESEÑAS DE LIBROS}

En el primer capítulo se presentan las unidades mínimas del discurso musical: signo, significante, significado, marcador, etcétera. Es destacable el subapartado The $W$ orld of Flats ("El mundo de los bemoles"), donde se explica un gesto recurrente en la música clásica y romántica: un cambio directo de tonalidad, sin modulación, a una tonalidad bemol. El autor explica que, normalmente, este gesto indica la irrupción en otra dimensión, respecto a lo que en el resto de la pieza se representaba como real, basándose en ejemplos de Mozart, Wagner, Chopin y Brahms. El lector se acostumbrará a encontrar no uno ni dos, sino múltiples ejemplos de compositores centrales del repertorio canónico, que dan fundamento a las propuestas analíticas del autor.

El punto 1.5 presenta el estado de la cuestión del campo de la Significación Musical. Una "breve revisión" que repasa en orden cronológico los nombres y eventos más destacables de esta disciplina emergente y que, sin duda, deberá ser citada en publicaciones posteriores, ya sea para confirmar o para refutar.

El segundo capítulo se centra en la música del Renacimiento y del Barroco, especialmente en los madrigalismos y las figuras retóricas, que sentaron las bases de la significación musical para los siglos posteriores. Adquieren especial importancia dos madrigalismos muy populares desde que surgieron en el madrigal del siglo XVI, y que a menudo se confunden. Se trata del 'Pianto' y la 'Suspiratio". Son dos topoi que siguen presentes actualmente, no hay más que fijarse en la banda sonora de la serie de televisión estadounidense Mad Men o en música contemporánea, como Lamento de Sofiya Gubaidúlina. El autor aclara estos dos topoi, que suelen aparecer dentro del mismo contexto, y sitúa el origen de la confusión entre ambos en el siglo XIX alemán.

El capítulo tercero profundiza en géneros y estilos, aquellos significados que derivan de la Historia de la Música. Por ejemplo, el Classic Mixed Style, que puede interpretarse como una fusión entre el estilo galante y el estilo académico (Learned Style). La música de compositores como Haydn, entendida como un estilo mixto, adquiere un gran poder expresivo. Además, Grimalt explica cómo este estilo mixto fue la piedra angular para la música académica occidental de los dos siglos posteriores. El autor ha escrito sobre una nueva visión del Clasicismo vienés en artículos como A Humorous Narrative Archetype in the Music of the Viennese Classics as a Subversive Device (Grimalt, 2018) y The political Beethoven through his instrumental music: some topical, narrative analyses (Grimalt, 2021) ${ }^{3}$.

A continuación, se presta atención a los campos semánticos: destaca el cuadro semiótico de la p. 118, que presenta los cuatro campos semánticos principales organizados en torno a dos ejes formados por las dicotomías Autoridad - Libertad y Espíritu - Cuerpo. Los cuatro campos semánticos corresponden a los principales lugares donde se hacía música en el siglo XVIII: 1) la iglesia, 2) el ejército, 3) el teatro y la cámara y 4) la sala de

\footnotetext{
${ }^{1} \mathrm{El}$ autor emplea las comillas simples a lo largo de todo el texto para las referencias y topoi, para diferenciar la referencia a un fenómeno, del propio fenómeno en sí.

${ }^{2}$ Grimalt, J. (2018). A Humorous Narrative Archetype in the Music of the Viennese Classics as a Subversive Device [Manuscrito no publicado]. International Congress on Musical Signification (ICMS) n. 14, Cluj (Rumanía).

${ }^{3}$ Grimalt, J. (2021). The political Beethoven through his instrumental music: some topical, narrative analyses [Manuscrito enviado para publicación]. Beethoven-Haus Bonn: Beethoven Perspectives: Proceedings of the International Conference.
} 


\section{RESEÑAS DE LIBROS}

baile. Cada uno de ellos lleva asociados significados expresivos y presenta relaciones de oposición, exclusión o complementariedad con los otros que se pueden representar gráficamente en un cuadro semiótico. Este cuadro semiótico no se presenta como el único ni definitivo, sino como una interpretación coherente y posible (p. 119). Esta posición dialogante y abierta del autor será recurrente a lo largo de todo el texto.

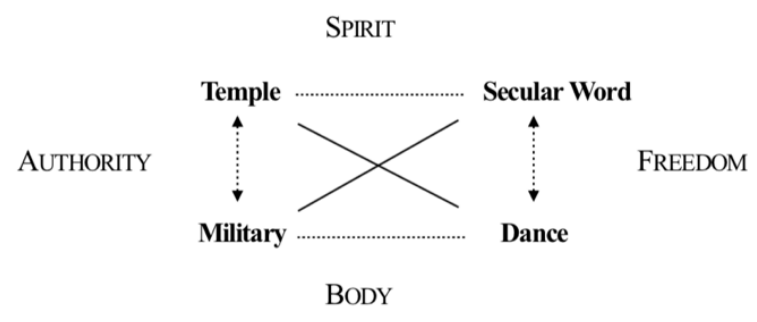

Figura 1. Cuatro campos semánticos en un cuadrado semiótico, (Mapping Musical Signification, p. 118).

Los siguientes cinco capítulos están dedicados a cada uno de esos campos semánticos: En primer lugar, aparecen las referencias a lo sagrado (Cap. 4). El capítulo comienza con una propuesta para el análisis tópico: el autor propone una diferenciación entre las referencias estáticas y las dinámicas, es decir, entre aquellas que tienen movimiento o un pulso regular, como las marchas o las danzas, y aquellas otras que no lo tienen, como el canto gregoriano que, al menos en su reconstrucción moderna, no tiene un pulso regular obvio. Grimalt explica cómo la cultura cristiana favoreció un tipo de espiritualidad que dejaba de lado lo corporal. Cuando la música moderna quiere representar el éxtasis o aspectos espirituales elevados, recurre a referencias sagradas, como la referencia al canto "no corporal", del cual el canto gregoriano es el modelo. Este éxtasis no tiene por qué ser religioso o místico, sino que puede tratarse también de un éxtasis amoroso, o pastoral. El capítulo propone ejemplos de Mozart y Vaughan Williams, entre otros. Otras referencias tratadas en este capítulo son el Dies Ire', tan popular en el siglo XIX como símbolo de muerte, el 'Stile Antico' procedente del motete polifónico, recurso fundamental en la obra de Bach, Haydn y Mozart. El autor repasa cronológicamente este topos y nos muestra cómo evoluciona y qué matices va adquiriendo su significado históricamente. Se muestra así que los topoi son conceptos variables y vivos, no unívocos, y que se van cargando de matices a medida que una nueva época los emplea.

El capítulo 5 se encarga de las referencias marciales, como la 'Obertura francesa' y la discutida cuestión del ritmo punteado. Se presta atención al prólogo de los Madrigali guerrieri ed amorosi (1683) de Monteverdi, donde se realiza, con una intención claramente expresiva, una descripción de tres estilos: estilo concitato (agitado), estilo temperato (moderado) y estilo molle (suave). 
RESEÑAS DE LIBROS

\begin{tabular}{l|l|l}
\hline \multicolumn{1}{c|}{ STYLE } & \multicolumn{1}{|c|}{ PASSION } & \multicolumn{1}{c}{ VOCAL RANGE } \\
\hline Concitato (agitated) & Wrath & High \\
\hline Temperato (moderate) & Temperance, moderation. & Middle \\
\hline Molle (soft) & Humility or Plea ${ }^{19}$ & Low \\
\hline
\end{tabular}

Tabla 2. Los tres estilos de Monteverdi (1638) (Mapping Musical Signification, p. 153).

Además, en las referencias marciales encontramos ritmos como el de anapesto, especialmente importante en la obra de Bach. Las llamadas de caza y las fanfarrias han sufrido un proceso de estilización que se explica en el punto 5.2 Calls, Fanfares, con ejemplos desde Palestrina hasta Mahler. Destaca el punto 5.3 Classic 'March': Irony. A 'Toy Army', que explica cómo los clásicos vieneses utilizaban en muy raras ocasiones las referencias a la marcha en un sentido literal, sino que en general tenían un sentido irónico. Seguidamente, el autor describe la 'Marcha disfórica', y sus marcadores: modo menor, tempo moderado, dinámicas piano, carácter sombrío, 'unísono siniestro', entre otros. Estos marcadores son los opuestos a los que definen la 'Marcha' en su versión "normal”.

\begin{tabular}{l|l|l}
\hline & \multicolumn{1}{|c}{ 'MARCH' } & \multicolumn{1}{c}{ 'DYSPHORIC MARCH' } \\
\hline Mode & Major & Minor \\
\hline Tempo & Fast & Moderate or slow \\
\hline Dynamics & Forte & piano \\
\hline Character & Energetic & Gloomy \\
\hline Texture & Homophonic & Unison \\
\hline Diastematic & Triadic, diatonic, imitating cornets and drums \\
\hline
\end{tabular}

Tabla 3. Marcadores de dos topoi marciales (Mapping Musical Signification, p. 190)

El volumen continúa con las referencias seculares: lo lírico y lo pastoral (Cap. 6), referencias a las danzas (Cap. 7) y referencias teatrales (Cap. 8). La clasificación de esta gran cantidad de referencias se ve beneficiada por el ejercicio sintético del autor y la riqueza de los ejemplos musicales planteados, que sugieren una amplia experiencia del autor como intérprete. Del capítulo séptimo destaca la explicación de la doctrina del tempo giusto de J. $\mathrm{Ph}$. Kirnberger ${ }^{4}$, fundamental para entender la música de los siglos posteriores.

El último capítulo reivindica la importancia de la ópera y el teatro para la comprensión de la música instrumental. Revisa la ópera cómica y sus orígenes, así como los de la ópera trágica. El recitativo secco y el accompagnato constituyen una fuente de referencias en toda la música instrumental. El capítulo continúa con una explicación de la reforma de la ópera de Gluck, el dramma giocoso, el melodrama germánico, y llega a las referencias cómicas (8.4. Comic references), donde se evidencia la estrecha relación entre la ópera cómica y la música instrumental de compositores como Mozart o Haydn. El punto 8.5 habla de las referencias a la ópera trágica que han llegado a la música instrumental, como la 'Tempesta' ('Tormenta'), el 'Ominous Unison' ('Unísono Siniestro') o la 'Ombra' ('Sombra').

\footnotetext{
${ }^{4}$ Kirnberger, J. Ph. (1776). Die Kunst des reinen Satzes in der Musik, vol. II, 1, IV. Berlín y Königsberg: Decker und Hartung.
} 


\section{RESEÑAS DE LIBROS}

En un campo tan novedoso y emergente como es el de la Significación Musical, algunos conceptos han sido definidos y utilizados por diferentes teóricos bajo criterios diferentes, lo cual ha sido y es objeto de críticas por parte de musicólogos de otras disciplinas o incluso de la misma. Por ejemplo, en Approaches to meaning in music (Byron Almén y Edward Pearsall, 2006), se reflexiona sobre la ambigüedad del término meaning, argumento que se utiliza muchas veces para desacreditar esta disciplina. El término es muy amplio y reciente, por lo que diferentes escritores le atribuyen un significado u otro. Esto ocurre con la mayoría de los conceptos en uso en la musicología del significado: topos, pianto, suspiratio, isotopía, carácter, gesto musical... La respuesta de Grimalt parece ser un estudio sólido de la historia de cada término. El autor muestra un conocimiento detallado de las publicaciones relacionadas y ofrece un resumen de los diferentes términos que ha empleado cada autor, ordenados cronológicamente, lo cual sitúa su discurso dentro de un proceso dialógico, en el que diferentes personas dan argumentos basados en pretensiones de validez y no de poder.

La obra se sitúa dentro de la colección Numanities, editada por Dario Martinelli. El autor reivindica la Significación Musical como parte de las Humanidades, con un trasfondo filosófico y político implícito. En sus propias palabras: "al poner humildemente palabras a la experiencia musical inefable e irreductible, la reflexión sobre los significados expresivos de la música tiene la gran ambición de hacer el mundo más humano, menos cruel e injusto" (Grimalt, 2020, p. XV).

El libro se puede adquirir a través de la página web de Springer en formato digital o físico, y en las principales librerías y plataformas digitales. El precio del formato físico, difícilmente asequible para estudiantes, entra en conflicto con la intención pedagógica manifestada por el autor, y únicamente puede verse compensado gracias a la potente tarea de distribución realizada por Springer. El volumen está disponible para préstamo en las bibliotecas de la mayoría de Conservatorios Superiores y Bibliotecas Públicas no sólo del país, sino de las principales ciudades de todo el mundo.

Cristina González Rojo

Escola Superior de Música de Catalunya 